\title{
Neonatal hyperinsulinism in transient and classical forms of tyrosinemia
}

\author{
Swathi Sethuram ${ }^{1 *} \mathbb{0}$, Mark A. Sperling ${ }^{1}$, Jasmine Gujral ${ }^{2}$ and Christopher J. Romero ${ }^{1}$
}

\begin{abstract}
Background: The spectrum of disorders associated with hyperinsulinemic hypoglycemia (HHI) has vastly increased over the past 20 years with identification of molecular, metabolic and cellular pathways involved in the regulation of insulin secretion and its actions. Hereditary tyrosinemia (HT1) is a rare metabolic disorder associated with accumulation of toxic metabolites of the tyrosine pathway due to a genetically mediated enzyme defect of fumarylacetoacetate hydrolase. Transient tyrosinemia of the newborn (TTN) is a benign condition with a maturational defect of the enzymes associated with tyrosine metabolism without any genetic abnormalities.

Results: We describe two rare cases of HHI, one in a patient with $\mathrm{HT} 1$ and for the first time, in a patient with TTN. Each of our patients presented in the neonatal period with persistent hypoglycemia that on biochemical evaluation was consistent with $\mathrm{HHI}$. Each patient received diazoxide therapy for 3.5 months and 17 months of life, respectively and $\mathrm{HH}$ resolved thereafter.

Conclusion: Despite the fact that HHI has been described in $\mathrm{HT} 1$ for several decades, no specific mechanism has been delineated. Although we considered the common embryonal origin of the liver and pancreas with the hepatotoxic effect in HT1 also impacting the latter, this was not a possible explanation for TTN. The commonality between our two patients is the accumulation of certain amino acids which are known to be insulinotropic. We therefore hypothesize that the excess of amino acids such as leucine, lysine, valine and isoleucine in our patients resulted in $\mathrm{HHI}$, which was transient. Both patients responded to diazoxide. This novel presentation in TTN and the reassuring response in both $\mathrm{HT} 1$ and TTN to diazoxide will be useful to inform physicians about managing $\mathrm{HH}$ in these patients. Further studies are required to delineate the mechanism of $\mathrm{HHI}$ in these infants.
\end{abstract}

Keywords: Hyperinsulinism, Hypoglycemia, Hyperinsulinism in hereditary tyrosinemia I, Transient tyrosinemia of the newborn, Amino acids and hyperinsulinism, Hyperinsulinemic hypoglycemia

\section{Background}

Our knowledge of the metabolic and molecular basis of hyperinsulinemic hypoglycemia of infancy (HHI) has dramatically increased over the past 20 years $[5,6$, 9, 18]. Monogenic forms of HHI have been identified with defects in the pancreatic ATP sensitive potassium

\footnotetext{
*Correspondence: swathi.s.ram@gmail.com

1 Division of Pediatric Endocrinology and Diabetes, Department of Pediatrics, Icahn School of Medicine at Mount Sinai, 1 Gustave L. Levy Place, Box 1616, New York, NY 10029, USA

Full list of author information is available at the end of the article
}

(KATP) channels, transcription factors and enzymes of the insulin secretory pathway resulting in excessive production and secretion. Syndromic forms of HHI form a separate entity of genetic HHI disorders, which include Beckwith Wiedemann Syndrome, Kabuki Syndrome, Turner Syndrome and Hereditary Tyrosinemia Type I (de Leon and Stanley 2017) [10, 18].

Hereditary Tyrosinemia Type 1 (HT1, OMIM \# 276700) is a rare autosomal recessive disorder with an estimated incidence of 1:100,000 [4]. HT1 results from an inability to metabolize the amino acid tyrosine due to deficiency of the enzyme fumarylacetoacetate hydrolase original author(s) and the source, provide a link to the Creative Commons licence, and indicate if changes were made. The images or other third party material in this article are included in the article's Creative Commons licence, unless indicated otherwise in a credit line to the material. If material is not included in the article's Creative Commons licence and your intended use is not permitted by statutory regulation or exceeds the permitted use, you will need to obtain permission directly from the copyright holder. To view a copy of this licence, visit http://creativecommons.org/licenses/by/4.0/. The Creative Commons Public Domain Dedication waiver (http://creativeco mmons.org/publicdomain/zero/1.0/) applies to the data made available in this article, unless otherwise stated in a credit line to the data. 
(FAH, EC number EC Number: 3.7.1.2) encoded by the FAH gene (Gene ID: 2184) on chromosome 15q25.1. This leads to the accumulation of succinylacetone, a toxic metabolite, resulting in damage to the liver, kidneys and peripheral nerves. HT1 has a broad spectrum of clinical presentations, which may be complicated by liver and kidney dysfunction if not appropriately treated $[3,15]$.

In contrast to HT1, transient tyrosinemia of the newborn (ORPHA:3402) is considered to be a benign condition caused by a maturational delay in the enzymatic action of the tyrosine catabolic process without any genetic mutation. This condition resolves spontaneously after several months of life and generally is without longterm sequelae [22].

HHI has rarely been reported in infants with HT1, but to date no cases have been reported in patients with transient tyrosinemia of infancy $[1,3]$.We describe two unrelated patients with $\mathrm{HHI}$ in infancy, one with genetic and the other with transient forms of tyrosinemia. To maintain euglycemia, both patients initially required diazoxide, which was eventually discontinued in each of them.

We hypothesize that the metabolic derangements associated with tyrosinemia place a patient at risk for hyperinsulinism that may require pharmacological treatment. With scarce literature available on the subject, we explore some possible mechanisms for the etiology of this presentation in both these forms of tyrosinemia. This report should alert clinicians to the possible risk for hypoglycemia and its resolution with diazoxide treatment in patients with tyrosinemia, and highlights the need for further mechanistic studies.

\section{Case presentations}

\section{Patient 1}

This is a female infant born appropriate for gestational age [birth weight: $2.6 \mathrm{~kg}(\mathrm{Z}=-0.71 \mathrm{SD})$, birth length: $50 \mathrm{~cm}(\mathrm{Z}=0.78 \mathrm{SD})]$ at 37 weeks to a healthy mother [Gravida (G) 5,Parity (P)2], with no significant prenatal history. Physical examination at birth was unremarkable. The patient developed hypoglycemia at $2.5 \mathrm{~h}$ of life, with a point of care (POC) glucose measurement of $0.72 \mathrm{mmol} / \mathrm{L}(13 \mathrm{mg} / \mathrm{dL})$. The patient required a combined glucose infusion rate (GIR) of up to $12 \mathrm{mg} / \mathrm{kg} / \mathrm{min}$ [intravenous (IV) dextrose plus oral feeds] to maintain euglycemia. A critical sample was drawn when the plasma glucose was $1.9 \mathrm{mmol} / \mathrm{L}$ $(34 \mathrm{mg} / \mathrm{dL})$ on day of life 5 to evaluate the corresponding insulin and counter-regulatory hormone response (Table 1). Hyperinsulinism was diagnosed based on the elevated serum insulin $(30.6 \mathrm{pmol} / \mathrm{L}$ or $4.4 \mathrm{uU} / \mathrm{ml})$ and C-peptide level $(0.004 \mathrm{nmol} / \mathrm{L}$ or $1.1 \mathrm{ng} / \mathrm{mL})$ with undetectable serum ketone levels (Table 1). Normal growth hormone and cortisol levels ruled out pituitary or adrenal dysfunction. The newborn screening test (drawn on day of life 3 and 22) reported elevated tyrosine levels in blood, but urine succinylacetone was negative, indicating that this was not HT1. The consulting genetic-metabolic team considered this to be transient tyrosinemia of infancy. Despite being on ad lib oral feeds with fortified $(24 \mathrm{kcal} / 30 \mathrm{~mL})$ formula, the patient continued to have intermittent hypoglycemic episodes (less than $3.3 \mathrm{mmol} / \mathrm{L}$ or $60 \mathrm{mg} / \mathrm{dL}$ beyond day 3 of life). Hence, diazoxide was started at two weeks of life at a dose of $12 \mathrm{mg} / \mathrm{kg} /$ day along with hydrochlorothiazide at $1 \mathrm{mg} / \mathrm{kg} /$ day. Thereafter, no further hypoglycemia or treatment-induced hyperglycemia was recorded. Given consistently normal blood glucose, the same diazoxide dose was continued during subsequent follow up visits, resulting in a lower per kilogram body weight dosing. The parents discontinued her medications at 3.5 months of life, while continuing to monitor her glucose levels via a POC glucose meter. She has since remained euglycemic with appropriate growth and development for age. Her transient tyrosinemia resolved biochemically when tested at 6 months of life and she was subsequently discharged from the endocrine clinic at 7 months of life.

Table 1 Patient profiles during hypoglycemia

\begin{tabular}{|c|c|c|}
\hline & Patient 1 & Patient 2 \\
\hline Laboratory samples (values consistent with hyperinsulinemic hypoglycemia) $[7,13]$ & Transient tyrosinemia of infancy & $\begin{array}{l}\text { Hereditary } \\
\text { tyrosinemia } \\
\text { type I }\end{array}$ \\
\hline Preserved plasma glucose < 3.3 mmol/L (<60 mg/dL) & $1.9(34)$ & $2.2(39)$ \\
\hline Beta-hydroxy butyrate $<1.8 \mathrm{mmol} / \mathrm{L}$ & $<0.2$ & $<0.2$ \\
\hline C-peptide $>0.002 \mathrm{nmol} / \mathrm{L}(>0.5 \mathrm{ng} / \mathrm{dL})$ & $0.004(1.1)$ & $0.007(2.1)$ \\
\hline Insulin > $13.9 \mathrm{pmol} / \mathrm{L}(>2 \mathrm{uU} / \mathrm{mL})$ & $30.6(4.4)$ & $20.8(3)$ \\
\hline Growth hormone > $7.5 \mathrm{ug} / \mathrm{L}(>7.5 \mathrm{ng} / \mathrm{mL})$ & $17(17)$ & $7.5(7.5)$ \\
\hline Cortisol 496 nmol/L (> 18 mcg/dL) & $551.8(20)$ & $689.7(25)$ \\
\hline
\end{tabular}




\section{Patient 2}

This is a male infant born appropriate for gestational age [birth weight: $3.68 \mathrm{~kg}(\mathrm{Z}=1.24 \mathrm{SD})$, birth length: $52.1 \mathrm{~cm}(Z=1.24 \mathrm{SD}])$ at 38 weeks to a G1P1 mother who developed gestational diabetes requiring insulin therapy from the $8^{\text {th }}$ month of pregnancy. At birth, physical examination was normal with no signs of dysmorphia. The patient was born at a regional hospital where he required IV fluids for hypoglycemia which was attributed to him being an infant of a diabetic mother. However, his hypoglycemia persisted with repeated POC glucose readings as low as $0.72 \mathrm{mmol} / \mathrm{L}$ (13 $\mathrm{mg} / \mathrm{dL})$. He received intravenous dextrose infusion in addition to oral feeds, requiring a combined GIR of up to $13.6 \mathrm{mg} / \mathrm{kg} / \mathrm{min}$ to maintain euglycemia. His newborn screening test (drawn on day of life 2) was positive for elevated levels of succinylacetone, suggestive of HT1. The diagnosis of HT1 was confirmed by identifying a homozygous pathogenic mutation, c.192G > T, p.Q64H in the FAH gene. He was treated with nitisinone (2-[2-nitro-4-trifluoromethylbenzoyl]1,3-cyclohexanedione, NTBC) and a tyrosine-free formula from day 9 of life. His tyrosine levels did normalize with this therapy by day 12 of life. However, he continued to have recurrent hypoglycemic episodes after two weeks of life. To establish a diagnosis for his hypoglycemia, a critical sample was drawn when his plasma glucose level was $2.2 \mathrm{mmol} / \mathrm{L}$ (39 mg/dL). Undetectable $\beta-\mathrm{OH}$ butyrate $(<0.2 \mathrm{mmol} / \mathrm{L})$ with elevated C-peptide $(0.007 \mathrm{nmol} / \mathrm{L}$ or $2.1 \mathrm{ng} / \mathrm{mL})$ and insulin levels $(20.8 \mathrm{pmol} / \mathrm{L}$ or $3 \mathrm{uU} / \mathrm{mL}$ ) in this sample (Table I1 led to the diagnosis of hyperinsulinism. Serum growth hormone and cortisol showed an appropriate response to the hypoglycemia indicative of normal pituitary and adrenal function (Table 1). He was started on treatment with diazoxide at $10 \mathrm{mg} / \mathrm{kg} /$ day at two weeks of life, which stabilized glycemic control without additional need for intravenous glucose. Following discharge from the neonatal intensive care unit, the baby had moderate control of his tyrosinemia with nitisinone and dietary management. He did not have any further hypoglycemic episodes while on diazoxide. The patient gained adequate weight in the first year of life with appropriate development for age. Diazoxide dose was gradually weaned to sub-therapeutic levels $(1.5 \mathrm{mg} / \mathrm{kg} /$ day $)$ and discontinued at 17 months of life. The patient had one episode of hypoglycemia during an upper respiratory tract illness after stopping therapy. Diazoxide has since then not been restarted and the baby remains euglycemic to date.

\section{Discussion}

We report two cases of neonatal hyperinsulinemic hypoglycemia in the setting of tyrosinemia; one case with hereditary tyrosinemia type I, which has been previously reported and another case with transient tyrosinemia of the newborn, which to our knowledge has not been described.

Despite similar nomenclature, Hereditary Tyrosinemia Type I and transient tyrosinemia of infancy have very different pathophysiology and prognosis. While the former is a permanent, genetic condition with significant morbidity and mortality, the latter is a benign and transient immaturity of enzyme(s). The common factor in both conditions, however, is the accumulation of tyrosine.

Hypoglycemia may affect up to $10 \%$ of healthy term infants in the first 24-48 h of life, but typically resolves spontaneously by day three of life. Screening and treatment of hypoglycemia is important to prevent adverse neurological sequelae. There remains some debate over the definition of hypoglycemia in the neonatal period and the glucose levels at which neurological development may be affected. More recently, the Pediatric Endocrine Society recommended treatment in patients with plasma glucose $<2.8 \mathrm{mmol} / \mathrm{L}(<50 \mathrm{mg} / \mathrm{dL})$ in the first $48 \mathrm{~h}$ of life and $<3.3 \mathrm{mmol} / \mathrm{L}(<60 \mathrm{mg} / \mathrm{dL})$ beyond $48 \mathrm{~h}$ of life [19-21].

Both of our patients presented with significant hypoglycemia during their first few days of life that persisted up to 2 weeks of age. Hyperinsulinism was evident in each of these patients based on their biochemical evaluation during hypoglycemia. Mild liver dysfunction was documented in both patients which was not severe enough to account for such low glucose levels while receiving adequate alimentary nutrition.

Our first patient was diagnosed with transient tyrosinemia of infancy based on her biochemical evaluation. Based on our review of the literature, there has been no previous report of hyperinsulinism in infants with transient tyrosinemia, and although hypoglycemia has been described in patients with HT1, the mechanism of this presentation is not well understood $[1,3]$.

There are various etiologies of congenital hyperinsulinism, which include eleven monogenic forms as well as milder episodes as seen in infants with transient perinatal stress and prematurity [18]. Different amino acids have been known to induce positive as well as negative effects on beta cell insulin secretion [12].

Leucine is an amino acid whose well known insulinotropic effects are mediated by several different mechanisms, including the production of alpha ketoglutarate and allosteric activation of glutamate dehydrogenase $(G D H)$ [12]. Patients with leucine sensitive hypoglycemia were described as early as in 1960, 
although the mechanism was only understood after several decades [11]. Animal studies in sheep have demonstrated a rise in insulin secretion with intravenous administration of amino acids such as leucine, glycine, alanine, lysine and serine. Similarly, phenylalanine, a precursor to tyrosine, has been shown to induce insulin secretion in sheep although no such effects have been demonstrated with tyrosine [14].

Human studies have also demonstrated this insulinotropic effect of amino acids, both individually and in amino acid mixtures [8]. In an experiment in healthy humans, Fajans et al. elicited insulin release following IV infusion of certain amino acids. Infusion with arginine, lysine, leucine, phenylalanine, valine, methionine and histidine all resulted in insulin production with arginine being maximally potent and histidine the least [8].

Our first patient with transient tyrosinemia had transiently elevated levels of leucine, phenylalanine, isoleucine and valine (Table 2). The patient with HT1 had transient elevation of alanine, valine and lysine which normalized by two months of life. Both patients demonstrated elevated tyrosine levels (Table 2). We postulate that these elevated amino acids had transient insulinotropic effects, therefore manifesting as hypoglycemia in both patients.

In addition, reports have demonstrated that patients with HT1 have hyperplasia of the islet cells of the pancreas [16, 17]. This anatomical change, therefore, could reflect and be responsible for the hyperinsulinism causing significant hypoglycemia. In HT1, there is constant damage to hepatic tissue by toxic metabolites. This results in liver repair and nodule formation by activation of the stem cell compartment. There is evidence that stem cells and progenitor cells in the major duodenal papilla give rise to the biliary tree stem cells, which eventually lead to organogenesis of both the liver and the pancreas [2]. Given the common origin of liver and pancreatic cells,

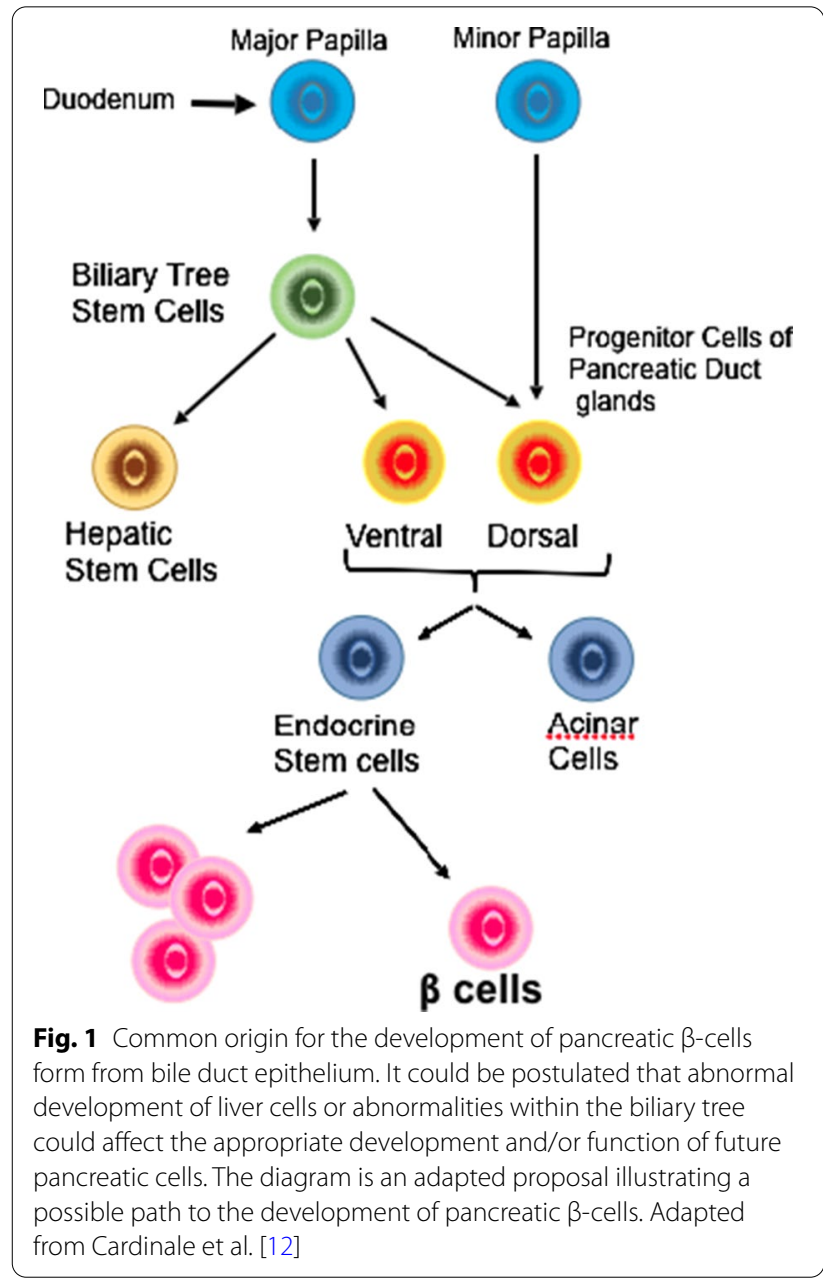

one could propose that inadvertent activation of stem cells could lead to hyperplasia of pancreatic islet cells in addition to hepatocytes, leading to hyperinsulinism (Figure 1). This theory, however, could not explain

Table 2 Amino acid levels in both infants

\begin{tabular}{|c|c|c|c|c|c|c|}
\hline \multirow{2}{*}{$\begin{array}{l}\text { Amino acid levels } \mu \mathrm{M} \\
\text { (normal values) }\end{array}$} & \multicolumn{3}{|l|}{ Patient I } & \multicolumn{3}{|l|}{ Patient II } \\
\hline & Day 19 of life & Day 22 of life & $\begin{array}{l}\text { Approximately } \\
2 \text { months of life }\end{array}$ & Day 7-8 of life & $\begin{array}{l}\text { Day } 12 \text { of life } 3 \text { days } \\
\text { after starting Nitisinone }\end{array}$ & 17 months of life \\
\hline Leucine 47-155 & $\Uparrow 164.1$ & $\Uparrow 166.7$ & 78.3 & 126.1 & 157.7 & 103.1 \\
\hline Alanine 131-710 & 534.8 & 526.6 & 352.7 & $\Uparrow 841.3$ & 628.6 & 302.3 \\
\hline Isoleucine 31-86 & $\Uparrow 92.9$ & $\Uparrow 102$ & 51.0 & 50.9 & 81.1 & 43.9 \\
\hline Valine 86-190 & $\Uparrow 258.3$ & $\Uparrow 234$ & 147.2 & $\Uparrow 265.7$ & $\Uparrow 290.5$ & 267.6 \\
\hline Lysine 52-196 & $\Uparrow 200.9$ & $\Uparrow 242.7$ & 127.4 & $\Uparrow 395.9$ & $\Uparrow 345.9$ & 69 \\
\hline Phenylalanine 31-75 & $\Uparrow 96.5$ & $\Uparrow 78.3$ & 41.3 & 53.6 & 12 & 72.6 \\
\hline Tyrosine 22-108 & $\Uparrow 904.3$ & $\Uparrow 660.5$ & $\begin{array}{l}\Uparrow 211.8 \\
\circledast 79(6 \text { months } \\
\text { of life) }\end{array}$ & $\Uparrow 506$ & 26.8 & $\Uparrow 426.4$ \\
\hline
\end{tabular}


hyperinsulinism in transient tyrosinemia where toxic metabolites do not accumulate.

We found one reported case series of three children with hyperinsulinemic hypoglycemia in the setting of HT1 that responded to diazoxide therapy [1]. All three patients required this medication only transiently, for 9, 18 and 34 months respectively. Our patient with HT1 required therapy until 17 months of life with some transient hypoglycemia during illness following discontinuation of medication. It is yet to be determined if his hypoglycemia will recur and require diazoxide again. However, hyperinsulinism in our patient with transient tyrosinemia was transient with discontinuation of therapy by 3.5 months of life.

\section{Conclusion}

In conclusion, we report the first incidence hyperinsulinism in a patient with transient tyrosinemia of infancy. We also report a patient with HT1 diagnosed with hyperinsulinism requiring diazoxide therapy until 17 months of life. Both cases had transient, but prolonged hyperinsulinism that was diazoxide responsive. Although hyperinsulinemic hypoglycemia has been reported in patients with HT1, no clear mechanism for this has been delineated. We postulate that the elevation of certain amino acids such as leucine, glycine, valine, phenylalanine and isoleucine could lead to excess insulin production. This hypothesis has not been previously proposed. Although pancreatic hyperplasia has been described in HT1, its mechanism is not clear. It seems more likely that amino acids stimulating insulin production result in islet cell hyperplasia. The common origin of the liver and pancreas does not explain the etiology of hyperinsulinism in transient tyrosinemia of infancy and hence cannot be invoked in this scenario. Nevertheless, the major novelty of our report is that clinicians should be alert about potential hypoglycemia in a patient diagnosed with either transient or hereditary tyrosinemia type I. Fortunately, we show these patients to be diazoxide responsive, so that euglycemia can be achieved in a relatively safe and effective manner. This report provides evidence of the transient nature of the hypoglycemia along with guidance for treatment to the health care provider and reassurance to the parents. Our proposed theory of amino acid induced hyperinsulinism is a known entity but has not been previously described with these metabolic disorders. Further studies are necessary to delineate the precise mechanism in these infants.

\section{Acknowledgements}

We would like to acknowledge the Pediatric Endocrinology Division at Icahn School of Medicine at Mount Sinai Hospital and the Neonatology unit for helping us care for these patients and collect required data to publish this article.

\section{Authors' contributions}

SS was involved in the conception, drafting and revision of all intellectual content of article. MAS was involved in conception and revising article critically for important intellectual content. JG was involved in revising article critically for important intellectual content. CR was involved in revising article critically for important intellectual content. All authors read and approved the final manuscript.

\section{Funding}

No external funding sources were used for this article.

\section{Availability of data and materials}

Data presented in this article is available in each of the patient's electronic medical record.

\section{Ethics approval and consent to participate}

Ethics approval and patient consents were not required for this study since no personal information was used and no human experiment conducted. All data have been deidentified for the purpose of this publication.

\section{Consent for publication}

Not applicable. Consent to publish was not required for this study since no personal information was used and no human experiment conducted.

\section{Competing interests}

SS received a travel award to present this data as a poster in the Hyperinsulinism symposium conducted at Children's Hospital of Philadelphia in September 2019. MAS is a consultant for the insulin advisory board for Novo Nordisk. JG has no competing interests. CR is a consultant for the Ascendis Advisory Board.

\section{Author details}

${ }^{1}$ Division of Pediatric Endocrinology and Diabetes, Department of Pediatrics, Icahn School of Medicine at Mount Sinai, 1 Gustave L. Levy Place, Box 1616, New York, NY 10029, USA. ²Division of Pediatric Endocrinology, Yale School of Medicine, New Haven, CT, USA.

Received: 9 June 2020 Accepted: 9 December 2020

Published online: 28 April 2021

\section{References}

1. Baumann U, Preece MA, Green A, et al. Hyperinsulinism in tyrosinaemia type I. J Inherit Metab Dis. 2005;28:131-5. https://doi.org/10.1007/ s10545-005-5517-1.

2. Cardinale V, Wang Y, Carpino G, et al. The biliary tree-a reservoir of multipotent stem cells. Nat Rev Gastroenterol Hepatol. 2012;9:231-40. https:// doi.org/10.1038/nrgastro.2012.23.

3. Chinsky JM, Singh R, Ficicioglu C, et al. Diagnosis and treatment of tyrosinemia type I: a US and Canadian consensus group review and recommendations. Genet Med. 2017;19:1380.

4. de Laet C, Dionisi-Vici C, Leonard JV, et al. Recommendations for the management of tyrosinaemia type 1. Orphanet J Rare Dis. 2013;8:8. https:// doi.org/10.1186/1750-1172-8-8.

5. de Leon DD, Stanley CA. Congenital hypoglycemia disorders: new aspects of etiology, diagnosis, treatment and outcomes: highlights of the proceedings of the congenital hypoglycemia disorders symposium, Philadelphia April 2016. Pediatr Diabetes. 2017;18(1):3-9.

6. de Lonlay P, Touati G, Robert J-J, Saudubray J-M. Persistent hyperinsulinaemic hypoglycaemia. Semin Neonatol SN. 2002;7:95-100. https://doi. org/10.1053/siny.2001.0090

7. Ferrara C, Patel P, Becker S, et al. Biomarkers of insulin for the diagnosis of hyperinsulinemic hypoglycemia in infants and children. J Pediatr. 2016;168:212-9. https://doi.org/10.1016/j.jpeds.2015.09.045.

8. Floyd JC, Fajans SS, Conn JW, et al. Stimulation of insulin secretion by amino acids. J Clin Invest. 1966;45:1487-502. https://doi.org/10.1172/ JCl105456.

9. Galcheva S, Demirbilek H, Al-Khawaga S, Hussain K. The genetic and molecular mechanisms of congenital hyperinsulinism. Front Endocrinol. 2019;10:111. https://doi.org/10.3389/fendo.2019.00111. 
10. Ghosh A, Banerjee I, Morris AAM. Recognition, assessment and manage ment of hypoglycaemia in childhood. Arch Dis Child. 2016;101:575-80. https://doi.org/10.1136/archdischild-2015-308337.

11. Grumbach MM, Kaplan SL. Amino acid and alpha-keto acid-induced hyperinsulinism in the leucine-sensitive type of infantile and childhood hypoglycemia. J Pediatr. 1960;57:346-62. https://doi.org/10.1016/S0022 3476(60)80242-9.

12. Keane K, Newsholme P (2014) Metabolic Regulation of Insulin Secretion. In: Vitamins \& Hormones. Elsevier, pp 1-33

13. Kelly A, Tang R, Becker S, Stanley CA. Poor specificity of low growth hormone and cortisol levels during fasting hypoglycemia for the diagnoses of growth hormone deficiency and adrenal insufficiency. Pediatrics. 2008;122:e522-8. https://doi.org/10.1542/peds.2008-0806.

14. Kuhara T, Ikeda S, Ohneda A, Sasaki Y. Effects of intravenous infusion of 17 amino acids on the secretion of $\mathrm{GH}$, glucagon, and insulin in sheep. Am J Physiol-Endocrinol Metab. 1991;260:E21-6. https://doi.org/10.1152/ajpen do.1991.260.1.E21.

15. Mudd SH. Hypermethioninemias of genetic and non-genetic origin: A review. Am J Med Genet C Semin Med Genet. 2011;157:3-32. https://doi. org/10.1002/ajmg.c.30293.

16. Perry TL. Tyrosinemia associated with hypermethioninemia and islet cell hyperplasia. Can Med Assoc J. 1967;97(18):1067-75.
17. Russo P, O'Regant S. Visceral pathology of hereditary tyrosinemia type I. Am J Hum Genet. 1990;47(2):317-24.

18. Stanley CA. Perspective on the genetics and diagnosis of congenital hyperinsulinism disorders. J Clin Endocrinol Metab. 2016;101:815-26. https://doi.org/10.1210/jc.2015-3651.

19. Stomnaroska-Damcevski O, Petkovska E, Jancevska S, Danilovski D. Neonatal hypoglycemia: a continuing debate in definition and management Pril Makedon Akad Na Nauk Umet Oddelenie Za Med Nauki. 2015;36:917. https://doi.org/10.1515/prilozi-2015-0083.

20. Thompson-Branch A, Havranek T. Neonatal hypoglycemia. Pediatr Rev. 2017;38(4):147-57. https://doi.org/10.1542/pir.2016-0063.

21. Thornton PS, Stanley CA, De Leon DD, et al. Recommendations from the pediatric endocrine society for evaluation and management of persistent hypoglycemia in neonates, infants, and children. J Pediatr. 2015;167:23845. https://doi.org/10.1016/j.jpeds.2015.03.057.

22. Transient Tyrosinemia of the newborn. https://www.orpha.net/consor/ cgi-bin/OC_Exp.php?lng=en\&Expert=3402

\section{Publisher's Note}

Springer Nature remains neutral with regard to jurisdictional claims in published maps and institutional affiliations.
Ready to submit your research? Choose BMC and benefit from:

- fast, convenient online submission

- thorough peer review by experienced researchers in your field

- rapid publication on acceptance

- support for research data, including large and complex data types

- gold Open Access which fosters wider collaboration and increased citations

- maximum visibility for your research: over $100 \mathrm{M}$ website views per year

At BMC, research is always in progress.

Learn more biomedcentral.com/submissions 